\title{
Combined linkage and association mapping reveal QTL for host plant resistance to common rust (Puccinia sorghi) in tropical maize
}

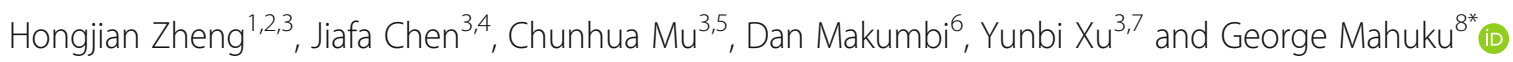

\begin{abstract}
Background: Common rust, caused by Puccinia sorghi, is an important foliar disease of maize that has been associated with up to $50 \%$ grain yield loss. Development of resistant maize germplasm is the ideal strategy to combat $P$. sorghi.

Results: Association mapping performed using a mixed linear model (MLM), integrating population structure and family relatedness identified 25 QTL $\left(P<3.12 \times 10^{-5}\right)$ that were associated with resistance to common rust and distributed on chromosomes 1, 3, 5, 6, 8, and 10. We identified three QTLs associated with all three disease parameters (final disease rating, mean disease rating, and area under disease progress curve) located on chromosomes 1, 3, and 8. A total of 5 QTLs for resistance to common rust were identified in the RIL population. Nine candidate genes located on chromosomes 1, 5, 6, 8, and 10 for resistance to common rust associated loci were identified through detailed annotation.

Conclusions: Using a diverse set of inbred lines genotyped with high density markers and evaluated for common rust resistance in multiple environments, it was possible to identify QTL significantly associated with resistance to common rust and several candidate genes. The results point to the need for fine mapping common rust resistance by targeting regions identified in common between this study and others using diverse germplasm.
\end{abstract}

Keywords: Puccinia sorghi, Genome-wide association study, maize diseases, Single-nucleotide polymorphisms

\section{Background}

Common rust of maize, caused by Puccinia sorghi Schwein, is widely distributed in tropical, subtropical, temperate, and highland environments, where it causes economic losses on approximately 7.8 million ha or $34 \%$ of the maize area [1]. Substantial losses in forage quality and up to $50 \%$ loss in grain yield have been observed [2]. Damage is caused by loss of photosynthetic leaf area, chlorosis and premature leaf senescence, leading to incomplete grain filling and poor yields. Common rust can be controlled by use of fungicides or resistant cultivars. For economic and ecological reasons, development and

\footnotetext{
* Correspondence: g.mahuku@cgiar.org

${ }^{8}$ International Institute of Tropical Agriculture (IITA), P.O. Box, 34443, Dar es Salaam, Tanzania

Full list of author information is available at the end of the article
}

deployment of resistant maize cultivars is the most appropriate strategy to minimize the effects of $P$. sorgh $i$, and significantly contribute to increased grain yield [3].

Previous research revealed that resistance of maize to common rust is controlled by both quantitative and qualitative genes [4-8]. Qualitative or major-gene resistance is controlled by single major-effect resistance genes that are either dominant or recessive and generally provide race-specific, high-level resistance, but in a non-durable manner. In contrast, quantitative resistance typically has a multi-genic basis and generally provides non-race-specific intermediate levels of resistance. In maize, more than 25 dominant $R p$ genes are involved in race-specific resistance for common rust and are organized in complex loci at chromosomes 3, 4, 6 and 10 [3, 9, 10]. Fourteen different resistance genes have been designated as $R p 1-A$ to $R p 1-N$ 
based on map position [11, 12] and a number of these have been genetically recombined, suggesting that they are encoded by members of a gene cluster [12, 13]. Subsequently, other genes from the rp1 loci designated $r p 5$ and $r p 6$ on chromosome $10[12,14] r p 3$ and $r p 4$ on chromosomes 3 and 4, respectively [15], $R p 7$ [16] and $R p 8$ on chromosome 6 [5] have been reported. The Rp1-D gene on chromosome 10 was cloned from the HRp1-D haplotype using transposon tagging [17], and further validated via a complementation test [18]. The $R p 1$ cluster was shown to vary widely in copy number (1-52 copies) among different maize haplotypes [19].

Single race-specific or major resistance genes confer high levels of resistance to specific rust biotypes, but simply inherited resistance may result in selection for virulent races. Although it is easier to work with qualitative resistance in crop genetic research and breeding, partial resistance to the diseases may be more durable than simply inherited resistance [20-22]. However, partial resistance has been more difficult to transfer than simply inherited resistance due to its presumed multigenic nature. Molecular mapping techniques in combination with marker-assisted selection, however, may enable breeders to more effectively identify and exploit this type of resistance.

Since the first mapping study of quantitative trait loci (QTL) in a plant was published in 1986 [23] a substantial number of studies have been conducted to map QTL for different disease resistances [3, 6, 7, 24-26]. Lübberstedt et al. [3] used European maize flint lines and identified 20 QTL conferring partial resistance to common rust distributed over all 10 maize chromosomes. Kerns et al. [6] used a segregating population from cross FRMo17 $\times$ BS11 $\quad($ FR)C7 and identified 24 molecular markers in 16 chromosomal regions that were significantly associated with partial rust resistance. Brown et al. [24], using an $F_{2: 3}$ population from a cross between sweet corn inbred lines IL731a and W6786, identified nine regions on six chromosomes, which were significantly associated with common rust severity. These mapping studies thus far have provided information on the genetic architecture of resistance to common rust, including the number, location, and action of chromosomal segments. Through linkage mapping, several $P$. sorghi resistance QTL have been identified [3-6, 8, 24], but these have not been validated for utilization by breeders. It is, therefore, important to identify new genes for resistance to common rust that can be effectively used in tropical maize breeding programs.

Genome-wide association studies (GWAS), based on linkage disequilibrium (LD) analysis, have become a useful tool for identifying and mapping causal genes with modest effects like common rust resistance genes [27, 28]. Three loci (chromosome 2, chromosome 3 and chromosome 8) associated with maize common rust resistance in temperate maize germplasm were identified using GWAS [8]. GWAS is particularly useful when large numbers of inbred lines are available, because once these lines have been genotyped they can be phenotyped in different environments across seasons/years, making it possible and cost-effective to study the genetic architecture of different traits using phenotypic data from multiple environments $[28,29]$. The traditional QTL mapping in bi-parental populations is powerful in comparing pairs of alleles, which gives a lower false discovery rate compared to GWAS. Hence, combining both GWAS and traditional QTL mapping maybe a powerful method for discovering causal loci across the genome $[26,30]$. In this study, we used GWAS in a diverse panel of tropical maize inbred lines and QTL mapping in a recombinant inbred line (RIL) population to analyze chromosomal regions associated with resistance to $P$. sorghi. The objectives were to localize and estimate the effects of minor and major loci for resistance to common rust using high density single nucleotide polymorphism (SNP) markers, and to identify candidate genes and potential causal polymorphisms for resistance to common rust through detailed annotation.

\section{Results}

\section{Phenotypic diversity}

The GWAS panel was evaluated at six environments for response to common rust and ratings were done three times for all environments except at Kenya09, where lines were evaluated once. Results showed very strong significant correlation between the three disease traits (AUDPC, FDR and MDR) (Table 1). Because disease rating at Kenya09 was evaluated once and strong correlation was observed between the three disease parameters, further analysis was conducted using only the FDR data. A weak negative correlation was observed between maturity (AD and SD) and rust resistance parameters (Table 1). Although rust resistance is a complex trait, the inoculum pressure was consistently high under field conditions and we obtained highly reliable phenotypic data, as shown by the within location repeatability of FDR that was $\geq 0.76$ (Table 2). The histogram of FDR

Table 1 Pearson correlation coefficients between three disease parameters and flowering traits

\begin{tabular}{llllll}
\hline & AUDPC & FDR & MDR & AD & SD \\
\hline AUDPC & 1 & $\cdot$ & $\cdot$ & $\cdot$ & $\cdot$ \\
FDR & $0.97^{* *}$ & 1 & $\cdot$ & $\cdot$ & $\cdot$ \\
MDR & $0.98^{* *}$ & $0.98^{* *}$ & 1 & $\cdot$ & $\cdot$ \\
AD & -0.25 & -0.25 & -0.24 & 1.00 & $\cdot$ \\
SD & -0.16 & -0.12 & -0.12 & $0.99^{* *}$ & 1.00 \\
\hline
\end{tabular}

AUDPC Area under the disease progress curve, FDR Final disease rating, MDR Mean disease rating, $A D$ Days to anthesis, $S D$ Silking date

**indicates significant at $P<0.01$ 
Table 2 Summary statistics and repeatability for final disease rating of common rust in a set of 296 DTMA panel inbred lines in six environments

\begin{tabular}{|c|c|c|c|c|c|c|}
\hline \multirow[b]{2}{*}{ Statistics } & \multicolumn{6}{|l|}{$\underline{\text { Location }}$} \\
\hline & BM09A & BM09B & Kenya09 & BM10 & BM11 & Celaya12 \\
\hline Range & $1.0-4.5$ & $1.0-4.5$ & $1.0-5.0$ & $1.0-5.0$ & $1.0-4.0$ & $1.0-5.0$ \\
\hline Mean (Panel) & 1.81 & 1.98 & 2.31 & 2.79 & 1.75 & 2.52 \\
\hline Mean (Resistant checks) & 1.5 & 1.92 & - & 1 & 1.17 & 1.33 \\
\hline Mean (Susceptible checks) & 3.75 & 4.17 & - & 4.67 & 4.25 & 4.77 \\
\hline Repeatability & 0.88 & 0.76 & 0.88 & 0.92 & 0.78 & 0.95 \\
\hline $\operatorname{LSD}_{(0.05)}{ }^{a}$ & 0.89 & 0.98 & 0.79 & 0.66 & 0.72 & 0.51 \\
\hline CV $(\%)^{b}$ & 49.4 & 39.9 & 33.8 & 41.3 & 31.5 & 33.3 \\
\hline
\end{tabular}

a LSD Least significant difference

${ }^{\mathrm{b}} \mathrm{CV}$ coefficient of variation

at each of the six environments showed a continuous distribution (Additional file 1), which suggested quantitative resistance genes might be responsible for most of the variation.

Highly significant differences $(P<0.001)$ among lines, environments and line $\times$ environment interaction were observed for FDR of common rust in the DTMA panel of inbred lines (Table 3). Several inbred lines exhibited differential response to common rust in various environments (Additional file 2). Genetic correlations for FDR among locations ranged from 0.48 to 1.00 (Table 4). Despite the significant line $\times$ environment interactions, strong genetic correlation coefficients among most of the environments were observed for FDR scores. Clustering of environments using FDR revealed two major clusters, with BA10 separated from other environments (Fig. 1). Environment BA10 had the smallest genetic correlations with other environments and was excluded from further analysis. The year of common rust evaluation at this location (2010) was extremely dry and therefore disease expression was affected.

\section{Genetic structure of DTMA panel of inbred lines}

The germplasm collection used in this study included 296 tropical maize inbred lines representing a large amount of the genetic diversity of CIMMYT and IITA's stress (drought, low nitrogen, acid soils, diseases, and entomology) breeding programs in Mexico, Colombia, Zimbabwe, Nigeria, Ethiopia and other tropical countries. Among the
55,000 SNP markers used to genotype the lines, 39,996 SNPs were scored for all lines. There was an even distribution of minor allele frequency across the 39,996 SNPs, out of which 7945 SNP markers (19.8\%) had a minor allele frequency (MAF) below 5\% across all tested lines. A total of 32,051 SNPs were used for population structure and association mapping after excluding SNPs with MAF below $5 \%$. The results showed that the panel had eight divergent groups, namely, I, II, III, IV, V, VI, VII and VIII (Fig. 2 and Additional file 3). Thus, structure analysis separated the germplasm clearly into different divergent groups.

\section{Genome wide SNP association}

Association mapping was performed using a mixed linear model (MLM) by integrating population structure (PCA) and family relatedness (kinship) within the DTMA panel using 32,051 SNPs with rare alleles $(\mathrm{MAF}<5 \%)$ having been excluded. A Bonferroni threshold $(1 / \mathrm{n})$ was used to show the significant polymorphic SNPs $\left(P<3.12 \times 10^{-05}\right.$ for 32,051 SNPs). In total, 37 SNP markers associated with common rust resistance were detected. Of the 37 SNP markers, seven SNP markers on four chromosomes (Chrs.1, 3, 6 and 8) were significantly associated with FDR $\left(P<3.12 \times 10^{-5}\right)$, seven SNP markers on three chromosomes (Chrs.1, 3 and 8 ) were significantly associated with MDR, and 23 SNP markers on five chromosomes (Chrs.1, $3,5,6,8$ and 10) were significantly associated with AUDPC (Table 5, Fig. 3a-h). The percentage of phenotypic

Table 3 Combined analysis of variance for final disease rating of common rust in a set of 296 Drought Tolerant Maize for Africa panel of inbred lines using combined data from evaluations conducted in 2009 to 2012

\begin{tabular}{|c|c|c|c|c|c|}
\hline Source of variation & Degrees of freedom & Sum of squares & Mean square & $F$ value & $P$ value \\
\hline Environment (Env) & 5 & 800.79 & 160.16 & 731.31 & $<1.0 \mathrm{E}-10$ \\
\hline Line & 295 & 2281.83 & 7.74 & 35.32 & $<1.0 \mathrm{E}-10$ \\
\hline Replication (Rep)/Env & 12 & 11.59 & 0.97 & 4.41 & 4.99E-07 \\
\hline Env $\times$ Line & 1450 & 1461.41 & 1.01 & 4.60 & $<1.0 \mathrm{E}-10$ \\
\hline Block(Env× Rep) & 687 & 217.12 & 0.32 & 1.44 & $<1.0 \mathrm{E}-10$ \\
\hline Error & 2782 & 609.26 & 0.22 & & \\
\hline
\end{tabular}


Table 4 Genetic (upper diagonal) and phenotypic correlations (below diagonal) for final disease rating (FDR) of common rust among locations

\begin{tabular}{lllllll}
\hline & BA09A & BA09B & Kenya09 & BA10 & BA11 & Celaya12 \\
\hline BA09A & 1 & 1.00 & 0.86 & 0.55 & 0.86 & 0.69 \\
BA09B & 0.79 & 1 & 0.88 & 0.55 & 0.92 & 0.73 \\
Kenya09 & 0.73 & 0.69 & 1 & 0.62 & 0.82 & 0.70 \\
BA10 & 0.36 & 0.35 & 0.42 & 1 & 0.52 & 0.48 \\
BA11 & 0.61 & 0.57 & 0.66 & 0.39 & 1 & 0.77 \\
Celaya12 & 0.67 & 0.59 & 0.74 & 0.47 & 0.73 & 1 \\
\hline
\end{tabular}

All the correlations were significant at the $P<0.01$ level

variance explained (PVE) by an individual significant SNP ranged from 6.43 to $12.97 \%$. Quantile-quantile plots (QQ plots) showed that population structure was controlled well by the mixed linear model (Additional file 4).

Based on the genomic region and size with significant SNPs, we classified these SNPs into 8 QTLs (Table 5). Five QTLs associated with FDR were detected, including one QTL denoted as rp6.1 (Bin 6.04 Pos $111 \mathrm{M}$ ) at Embu (Kenya) in 2009, one QTL denoted rp1.1 (Bin 1.06 Pos $192 \mathrm{M}$ ) at El Batan (Mexico) in 2010 and three QTLs denoted as rp3.1 (Bin 3.04 Pos 97 M), rp3.2 (Bin 3.04 Pos $115 \mathrm{M}$ ) and rp8.2 (Bin 8.05 Pos $141 \mathrm{M}$ ) at El Batan in 2011, respectively. Three QTLs associated with MDR were detected, including one QTL denoted as rp1.1 (Bin 1.06 Pos 192 M) at El Batan in 2010 and two QTLs denoted as rp3.1 (Bin 3.04 Pos $97 \mathrm{M}$ ) and $r p 8.2$ (Bin 8.05 Pos $141 \mathrm{M}$ ) at El Batan in 2011, respectively.

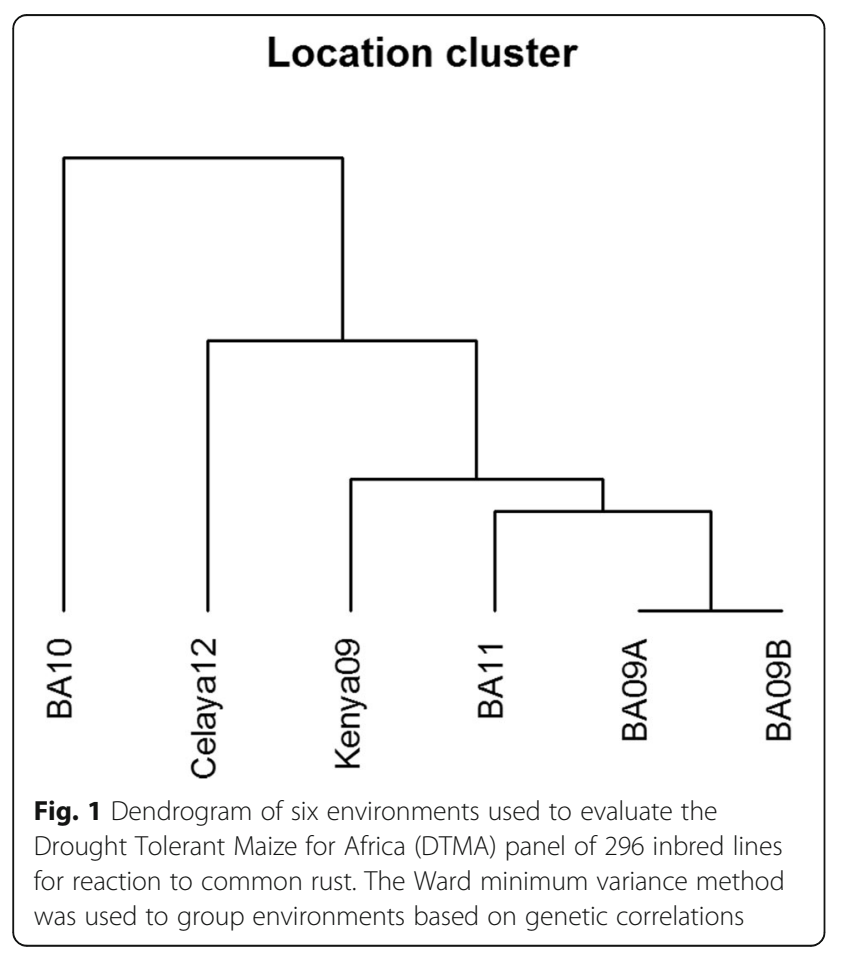

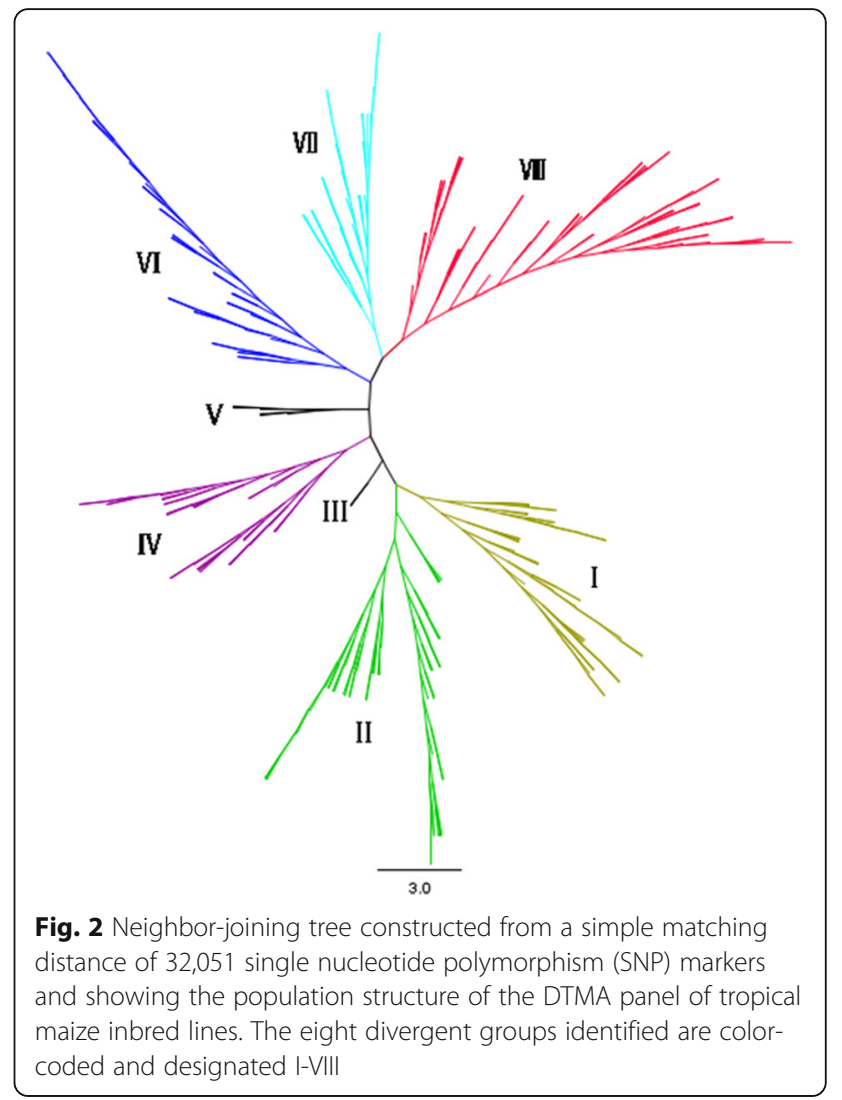

Six QTLs associated with AUDPC were detected, including three QTLs denoted as rp5.1 (Bin 5.02 Pos $10 \mathrm{M}$ ), rp8.1 (Bin 8.03 Pos 72-78 M) and rp10.1 (Bin 10.06 Pos $140 \mathrm{M}$ ) at El Batan in 2009, one QTL denoted as rp1.1 (Bin 1.06 Pos $192 \mathrm{M}$ ) at El Batan in 2010 and two QTLs denoting as rp3.1 (Bin 3.04 Pos $97 \mathrm{M}$ ) and rp8.2 (Bin 8.05 Pos $141 \mathrm{M}$ ) at El Batan in 2011, respectively.

There were three QTLs associated with all three disease parameters (FDR, MDR and AUDPC) which were located on Chr.1 (rp1.1), Chr.3 (rp3.1) and Chr.8 (rp8.2). All the QTLs associated with MDR were detected for AUDPC as well. One QTL (rp8.1) on Chr.8 associated with AUDPC was detected with several significant SNPs with high percentage of PVE $>10 \%$. It is notable that a significant QTL, rp3.1, detected for FDR, MDR and AUDPC at El Batan in 2011, was also detected at El Batan in 2009A, 2009B and 2010 with a low $P$ value, suggesting that $r p 3.1$ is likely to be a major QTL.

\section{Candidate genes annotation of associated SNPs}

Candidate genes were selected around the associated SNP (within $\sim 200 \mathrm{~kb}$ ) based on known involvement as metabolic or signaling genes in disease resistance. The gene annotation information was used to identify the putative function of genes around associated SNPs. Nine candidate genes were identified in the significant SNP 


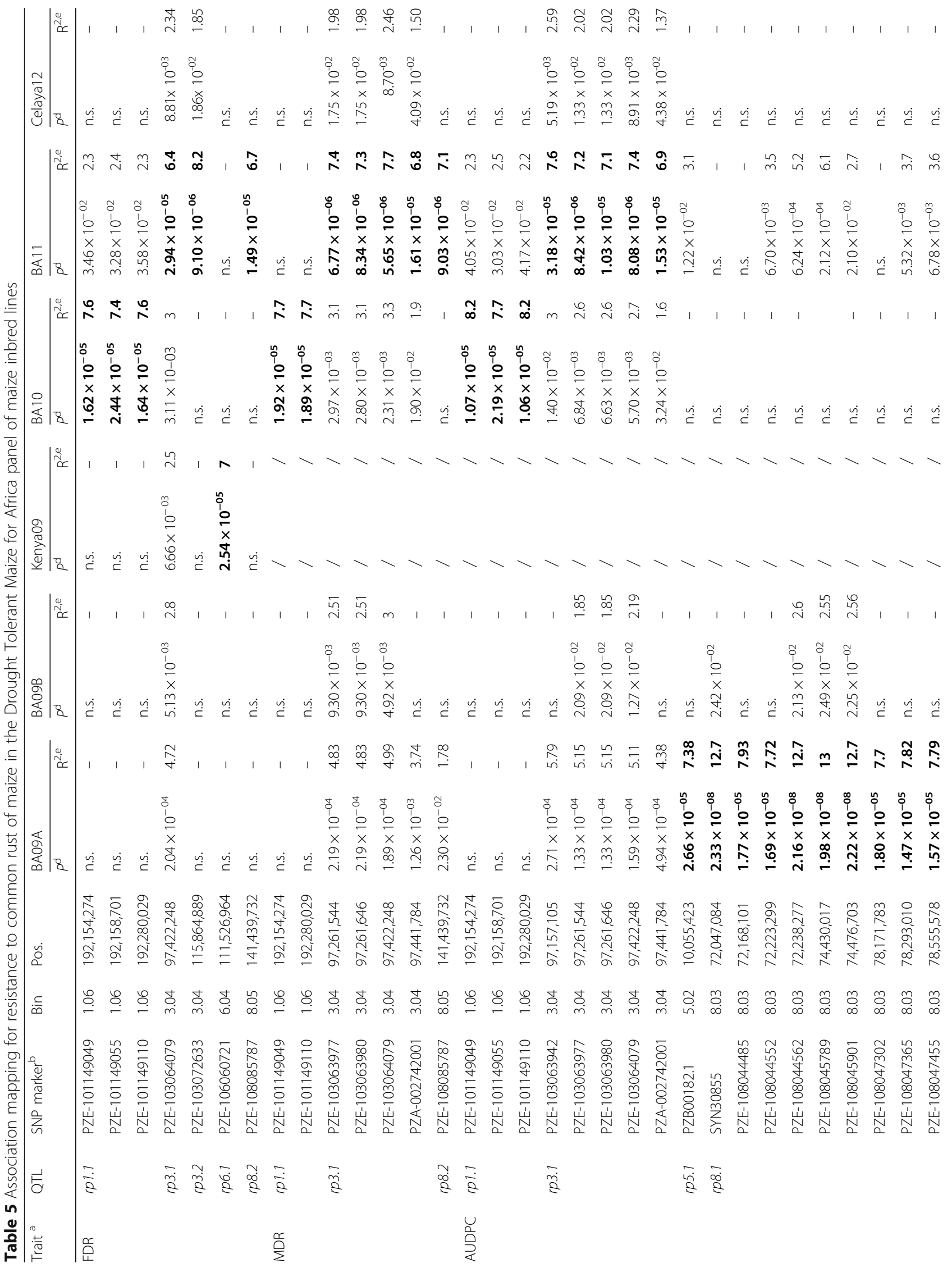




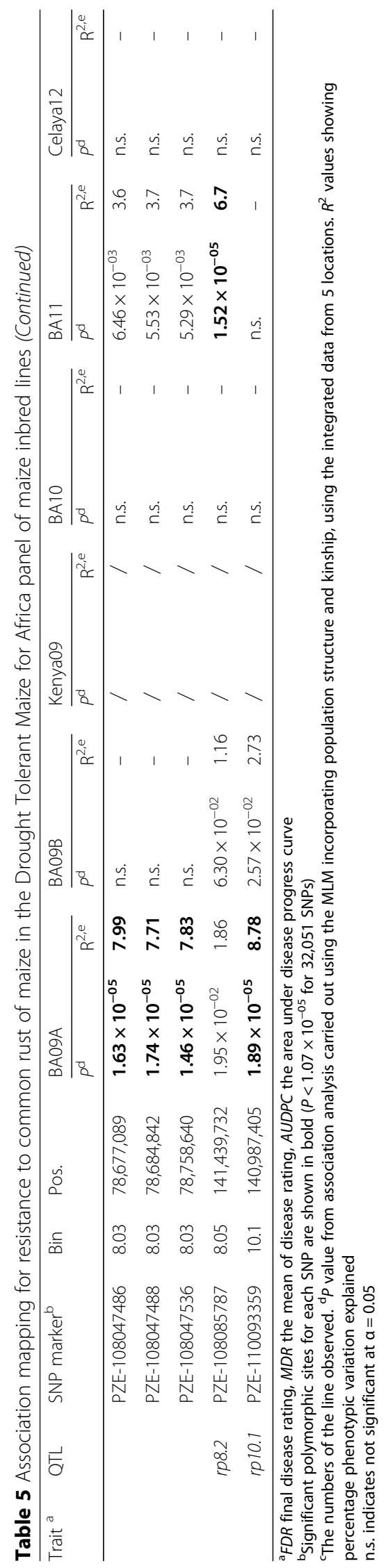


a

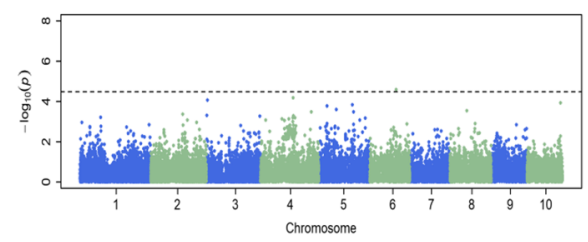

C

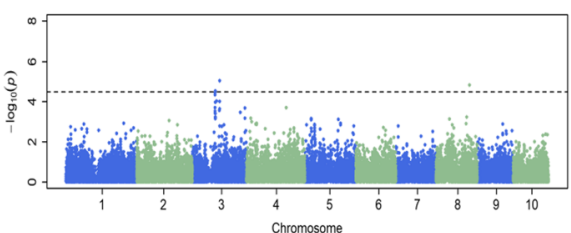

e

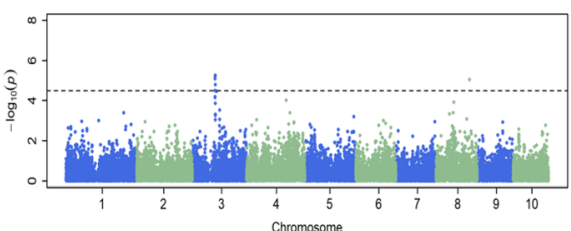

g

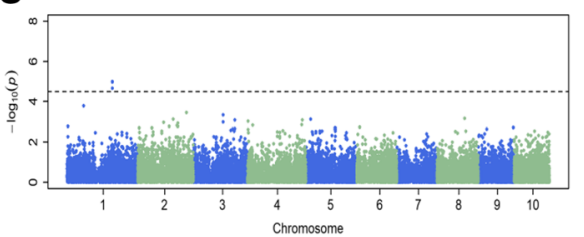

b

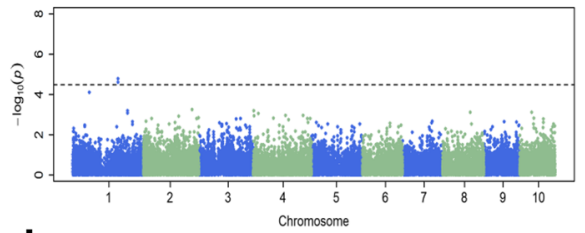

d

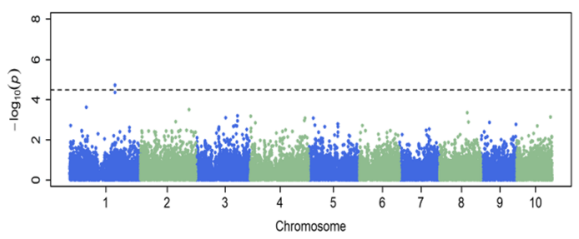

f

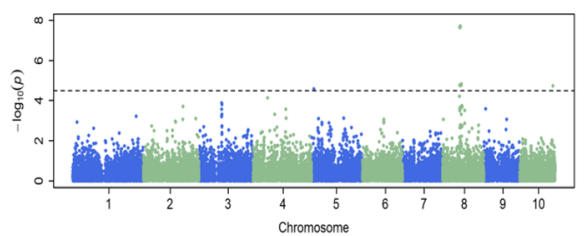

h

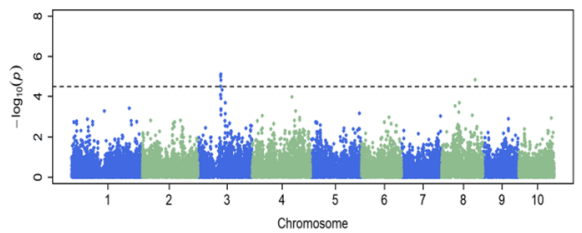

Fig. 3 Genome-wide association mapping of common rust resistance with 32,051 SNPs in Drought Tolerant Maize for Africa (DTMA) panel. The vertical axis indicates $-\log _{10}$ of $P$-value scores, and the horizontal axis indicates chromosomes and physical positions of SNPs. The dashed lines correspond to the thresholds of Bonferroni correction $\left(P<3 \times 10^{-5}\right)$. The Manhattan plots for significant SNP marker for different environments and disease evalution parameter. (a) One SNP marker on Chr. 6 associated with FDR in EK09; b) 3 SNP markers on Chr.1 associated with FDR in BM10; c) 3 SNP markers on Chr.3 and Chr.8 associated with FDR in BM11; d) 2 SNP markers on Chr.1 associated with MDR in BM10; e) 5 SNP markers on Chr.3 and Chr.8 associated with MDR in BM11, respectively; $\mathbf{f}) 14$ SNP markers on Chr.5, Chr.8 and Chr.10 associated with AUDPC ted in BM09A; g) 3 SNP markers on Chr.1 associated with AUDPC d in BM10; h) 6 SNP markers on Chr.3 and 8 associated with AUDPC BM1 1., respectively

sites (or adjacent to these sites) of six associated loci (Table 6). The combined approach was not effective for all loci because of the complexity of candidate gene identification. There were several association signals located in genomic regions with tandemly repeated genes. We identified nine candidate gene on chromosomes 1 , 5, 6, 8 and 10. Chromosome 5 had two candidate genes (GRMZM2G181002 at 10,084,848-10,087,159 bp, and GRMZM5G829476 at 10,117,318-10,118,871 bp) while chromosome 8 had four candidate genes (Table 6).

\section{QTL mapping for common rust}

The bi-parental RIL population was evaluated for common rust resistance in three environments. Significant phenotypic variation for rust resistance was observed among the RILs (Additional file 5). The genotypic variance $\left(\sigma_{G}^{2}\right)$ was significant $(P<0.01)$ at single environments. For combined ANOVA $\sigma_{\text {GE }}^{2}$ was significant $(P<0.01)$, suggesting common rust resistance is affected by environmental factors.
Broad-sense heritability was 0.72 across environments (Additional file 5), revealing that rust resistance was controlled by genetic factors and the data could confidently be used for QTL mapping.

Five QTL were detected in the RIL population, one each on Chr. 1 and 4, and three on Chr. 5 (Table 7). The QTL on Chr.5 (qRps5-1) had the highest LOD value (7.74) and it accounted for $18.37 \%$ of the total phenotypic variation observed for common rust resistance in the RIL population. The other two QTLs on Chr. 5 (qRps5-2 and qRps5-3) explained $15.84 \%$ of the phenotypic variation. Combined, the five QTLs detected in the RIL population explained $39.6 \%$ of the total phenotypic variance for common rust resistance.

\section{Discussion}

Genetic resistance to maize foliar diseases is the most important, economical and sustainable strategy for managing disease epidemics to increase maize production, 
Table 6 A subset of associated loci and candidate genes identified for common rust resistance according to gene annotation

\begin{tabular}{|c|c|c|c|}
\hline Chr. & Position (bp) ${ }^{a}$ & Candidate genes & Description \\
\hline 1 & $192,154,274$ & AC197246.3_FG001 ${ }^{b}$ & Ras-related protein ARA-4, small GTPase mediated signal transduction \\
\hline 5 & $10,055,423$ & GRMZM2G181002b $^{\mathrm{b}}, \mathrm{GRMZM} \mathrm{G} 829476^{\mathrm{b}}$ & Phosphotransferases. Serine or threonine-specific kinase subfamily \\
\hline 6 & $111,526,964$ & GRMZM2G156712 & FMN binding, kinase-associated protein, essential for defense against pathogens \\
\hline \multirow[t]{3}{*}{8} & $72,047,084$ & GRMZM2G157156 & PDZ/DHR/GLGF. Serine signalling proteases with PDZ domains \\
\hline & $78,171,783$ & GRMZM2G350684 $^{\mathrm{b}}, \mathrm{GRMZM}^{\mathrm{G}} \mathrm{G} 018048^{\mathrm{b}}$ & $\begin{array}{l}\text { SANT_DNA-bd. Novel transcriptional regulatory proteins that were identified } \\
\text { based on homology to the DNA binding domain of c-myb. }\end{array}$ \\
\hline & & GRMZM2G018142b & HAS protein. Found in helicases and associated with SANT domains \\
\hline 10 & $140,987,405$ & GRMZM2G109753 & $\begin{array}{l}\text { Scramblase protein, responsible for the translocation of phospholipids between } \\
\text { the two monolayers of a lipid bilayer of a cell membrane }\end{array}$ \\
\hline
\end{tabular}

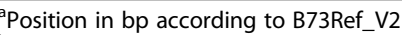

${ }^{\mathrm{b}}$ These genes have known involvement as metabolic or signaling genes in the disease resistance

especially for smallholder farmers. Development of open pollinated or synthetic maize varieties and hybrids resistant to major diseases requires sufficient information on the genetics and organization of resistance genes on the maize chromosome. This information will allow efficient strategies to combine or pyramid these genes in maize inbred lines that should allow resistant hybrid development. Genome-wide association studies that utilize diverse sets of inbred lines provide an avenue to precisely localize QTLs for quantitative traits and to potentially identify candidate genes [8]. This study used a combination of multiple environment phenotyping of a common set of inbred lines and association mapping to elucidate the genetics of maize resistance to common rust. Results from this study revealed relatively large repeatability estimates for response to common rust at single and across environments. This suggested that actual heritability estimates for common rust may be high, leading to higher genetic gain during selection for resistance to common rust. Higher repeatability estimates may also be attributed to the large diversity of the germplasm used.

Disease parameters, FDR and AUDPC are among those used to identify partial resistance to common rust in maize. Bailey et a1. [31] suggested the use of AUDPC to identify partial resistance to plant diseases for different crops, as this is an integrative parameter that measures the rate of disease progress as opposed to the final disease ratings. Hence, AUDPC can be useful in the identification of QTL that are associated with different components of disease resistance. Although a very strong correlation was observed between FDR and AUDPC $(r=0.97)$, these two parameters could be associated with different types of resistance. Three QTL, rp1 on Chr.1, rp3.1 on Chr.3 and rp8.2 on Chr.8, were detected by all three (FDR, MDR and AUDPC) disease parameters. All the QTL associated with MDR were detected with AUDPC. More SNPs were detected for AUDPC than for FDR, further indicating the importance of using different parameters in association mapping. Although it costs more (time and labor) to obtain data to calculate AUDPC because several ratings must be performed during crop development/growth cycle, our study has shown that it is more effective than a single score for QTL discovery.

Association analysis revealed common rust resistance QTLs on chromosomes 1, 3, 5, 6, 8 and 10, and these are in the regions that have previously been reported to harbor P. sorghi resistance [7]. Some of the QTL identified in this study have been mapped to regions previously described to be associated with common rust resistance through bi-parental population-based linkage analysis $[3,6,24]$ and other methods of analysis [5, 8, 32-34]. Lübberstedt et al. [3] reported that linkage groups 1 (bin1:05-1:06), 6 (6:04), and 10 (10:05-06) harbored important QTL for common

Table 7 Estimated quantitative trait loci (QTL) locations and genetic effects affecting common rust resistance in the CML444 $\times$ MALAWI RIL population

\begin{tabular}{|c|c|c|c|c|c|c|c|}
\hline QTL & Chr. & Position (cM) & Left Marker & Right Marker & LOD & PVE (\%) & Add \\
\hline aRps1-1 & 1 & 105 & PZA03742.1 & PHM12323.17 & 2.87 & 8.70 & -0.15 \\
\hline aRps4-1 & 4 & 28 & PHM3963.33 & umc1294 & 2.62 & 8.27 & 0.14 \\
\hline aRps5-1 & 5 & 118 & PZA02207.1 & PHM2769.43 & 7.74 & 18.37 & -0.22 \\
\hline aRps5-2 & 5 & 140 & PZA01349.2 & PZA01303.1 & 4.09 & 9.90 & -0.16 \\
\hline aRps5-3 & 5 & 193 & umc48b & npi237 & 2.65 & 5.94 & -0.12 \\
\hline
\end{tabular}

Chr. Chromosome, Add additive effect, PVE Phenotypic variation explained

Disease parameter used for QTL analysis was average common rust score 
rust resistance. In these regions, we also detected significant associations through GWAS, meaning that the action of these polymorphism loci may be influenced by linked QTL on the same chromosome. Brown et al. [24] identified QTL in bins 2.05 and 5.02 that confer partial resistance to common rust in maize. These bins correspond to association locations identified in our study. Two QTLs identified in this study (in bins 3.04 and 8.03) were also identified by Olukolu et al. [8]. This suggested the need to initiate a fine mapping study for common rust by targeting the common regions identified by various research groups with diverse germplasm. Furthermore, some association loci (rp8.1, $r p 8.2, r p 10.1)$ that confer partial resistance to common rust have not been previously reported. Chromosome 10 has been reported to harbor genes for resistance to southern corn rust [35] but we do not have information if it is the same or different set of genes as those for common rust. In our study, the QTL, rp3.1, detected using all three common rust resistance parameters (FDR, MDR and AUDPC) at El Batan in 2011, was also found at El Batan in 2009A, 2009B, and 2010 although with a non-significant low $P$ value. This suggests that rp3.1 may be a major QTL associated with resistance against common rust and it warrants further investigation.

Sources of quantitative disease resistance in crop plants have proven to be highly durable [36], making it a promising breeding target for long-term common rust resistance. The integration of resistance into adapted maize germplasm is, however, difficult because it is multi-genic, thereby making backcrossing inefficient. Difficulties in phenotyping common rust further complicate the breeding efforts. As with other diseases, breeding for common rust resistance requires artificial inoculation for uniform pathogen pressure to identify susceptible and resistant genotypes with little chance of escapes. In nature, the infrequent occurrence of the maize rust pathogen has resulted in inconsistent selection between environments, which has led to difficulties in selecting for and maintaining common rust resistance in maize breeding lines [37]. In the absence of selection pressure, resistance alleles may be lost, especially those with minor effects on resistance, as has occurred before [38]. In our study, no QTL was common across locations when using AUDPC, suggesting high pathogen variation among the locations. In this case, it might be more effective to use marker-assisted selection for loci linked to major and partial-resistance QTL to develop common rust resistant inbred lines and hybrids. Marker assisted selection has been successfully deployed for traits that are simply inherited, and is justified for such traits that are either too difficult or expensive to phenotype [39].

In this study, flowering time and common rust FDR were negatively correlated. This suggested that reaction to common rust was independent of genotype maturity. This result corroborates findings by Carson et al. [40] for southern leaf blight but is in contrast to Liu et al. [41] for gray leaf spot (GLS). Associated loci for FDR and flowering time did not co-localize (data not shown), a result that is in contrast to findings in other studies with maize diseases [40]. This is surprising since common rust, like other foliar diseases of maize, tends to be a late-season disease and earlier materials tend to escape.

In maize, host plant resistance genes are frequently found in clusters; however, the statistical power of current mapping techniques does not allow for further resolution of whether these genes are contiguous or allelic to known genes. Huang et al. [42] identified candidate genes for 18 associated loci through detailed annotation in rice, thus showing that the integrated approach of sequence-based GWAS and functional genome annotation has the potential to match complex traits to their causal polymorphisms. In our study, we identified candidate genes in the associated loci on chromosomes $1,5,6,8$, and 10 based on known involvement as metabolic or signaling genes in the corresponding traits. The four candidate genes identified on chromosome 8 are different from those reported in temperate germplasm by Olukolu et al. [8]. There were several association signals located in genomic regions with tandemly repeated genes. The candidate genes on chromosome 5 (GRMZM2G181002 and GRMZM5G829476) encode a phosphotransferases of serine or threonine-specific kinase (STK) subfamily, which play a key role in disease resistance system of plants, and were adjacent to associated loci SNP marker PZB00182.1 (Chr. 5 at 10,055,423 bp). Another gene, GRMZM2G156712 encoding a kinase-associated FMN binding protein, which is essential for defense against pathogens, was adjacent to associated loci SNP marker PZE-106060721 (Chr. 6 at 111,526,964 bp). Candidate genes near the significant associated loci detected by GWAS, maybe involved in the common rust resistance defense system in maize. More work is required to elucidate the potential function of these candidate genes.

\section{Conclusions}

We used a diverse set of inbred lines genotyped with high density markers and evaluated for common rust resistance in multiple environments, and identified QTL significantly associated with resistance to common rust and several candidate genes. The results of this study should be used to fine map common rust resistance by targeting the common regions identified between this and other studies that used different germplasm.

\section{Methods}

\section{Maize germplasm and phenotyping conditions}

A collection of 296 tropical maize inbred lines representing some of the genetic diversity available in CIMMYT's and IITA's stress breeding programs (drought, low N, acid soils, and biotic stresses) and denoted as Drought 
Tolerant Maize for Africa (DTMA) panel was used in this study (Table 8). The detail information about each inbred line constituting the panel is presented in Additional file 3.

The inbred lines were evaluated for response to $P$. sorghi in field trials in six environments in two countries. Field trials were planted in 2009, 2010 and 2011 in Mexico and in 2009 in Kenya (Table 9). Lines were planted in $2 \mathrm{~m}$ single-row plots, $0.75 \mathrm{~m}$ between rows, and $0.20 \mathrm{~m}$ within row to give a total of 10 plants per plot. Trails were laid out in an alpha-lattice design with three replications. Trials at El Batan (1952' N, 98 $84^{\prime}$ W; 2240 masl) in Mexico were artificially inoculated with $P$. sorghi isolates at the six to eight leaf stage. The El Batan experimental location harbors Oxalis latifolia, an alternate host of $P$. sorghi, the rust population at this location is complex as sexual reproduction takes place, resulting in new pathotypes, and therefore artificial inoculation was used. Another trial in Mexico at Celaya $\left(20^{\circ} 35^{\prime} \mathrm{N}\right.$, $100^{\circ} 49^{\prime}$ W; 1778 masl) was planted under natural disease pressure. The trial in Kenya was planted at Embu $\left(0^{\circ}\right.$ $30^{\prime} \mathrm{S}, 37^{\circ} 27^{\prime} \mathrm{E}$; 1350 masl) under natural disease pressure. Both Celaya and Embu are maize disease hotspots including common rust among others. The experimental design used was an alpha-lattice [43] with three replications at all locations. At Embu, plot length was a single $3 \mathrm{~m}$ row with inter and intra-row spacing of $0.75 \mathrm{~m}$ and $0.25 \mathrm{~m}$, respectively. A recombinant inbred line (RIL) population consisting of 234 families developed from the cross CML444 (R) $\times$ MALAWI (S) was also used. This RIL population was developed by Global Maize Program of CIMMYT using the single-seed descent method [44].
The RIL population and its two parents were planted for three seasons at El Batan in 2009 (BA09-1, BA09-2) and 2010 (BA10) to evaluate their reaction to common rust.

\section{Disease establishment and phenotyping}

Common rust epidemics were initiated artificially by injecting an aqueous suspension of $P$. sorghi spores $\left(60,000\right.$ spores $\left.\mathrm{ml}^{-1}\right)$ prepared by mixing sterile distilled water containing $0.03 \%$ Tween 20 into the whorl of maize plants at the 6-8 leaf stage. These procedures followed standard techniques for isolation, incubation, and inoculation for common leaf rust. Disease rating was conducted thrice at 15 day-intervals starting one week after silking at all locations, except Kenya09 where rating was done once at the peak of disease symptom expression. Disease rating was scored on five-point scale based on the percent leaf area affected by pustules and impact of the disease where $1=0$ to $10 \%$ of leaf surface diseased (no rust pustules or a few pustules scattered on the leaf surface), $2=10$ to $25 \%$ of leaf surface diseased (numerous pustules on the leaf surfaces), $3=25$ to $50 \%$ of leaf surface diseased (many pustules over the leaf surfaces), $4=50$ to $75 \%$ of leaf surface diseased (many pustules surrounded with huge blighted and sometimes rusty chlorotic zones), and $5=$ over $75 \%$ of leaf surface diseased (many huge dry pustules surrounded by dead rusty wilted and blighted areas on the leaves) (Fig. 4). The disease rating data were used to calculate the mean disease rating (MDR) and the area under disease progress curve (AUDPC). Mean disease rating (MDR) was calculated as:

Table 8 Origin, source and grain color of tropical maize inbred lines included in the Drought Tolerant Maize for Africa (DTMA) panel

\begin{tabular}{|c|c|c|c|c|c|}
\hline \multirow[t]{2}{*}{ Type } & \multirow{2}{*}{$\begin{array}{l}\text { Breeding program } \\
\text { of source germplasm }\end{array}$} & \multirow{2}{*}{$\begin{array}{l}\text { Number } \\
\text { of Lines }\end{array}$} & \multirow[t]{2}{*}{ Major categories } & \multicolumn{2}{|c|}{ Grain color } \\
\hline & & & & White & Yellow \\
\hline A & Zimbabwe & 41 & CMLs $^{a}$, CIMCALI, DTPW $^{b}$ & 41 & 0 \\
\hline B & Nigeria & 4 & KU, P43 & 2 & 2 \\
\hline C & Ethiopia & 2 & Pool9 & 2 & 0 \\
\hline D & Colombia & 27 & SA3, SA4, SA5, SA6, SA7, SA8 & 4 & 23 \\
\hline$E$ & Mexico highland & 5 & A.T.Z.T.R.L.BA90 & 1 & 4 \\
\hline $\mathrm{F}$ & Mexico entomology & 48 & CMLs, MBR ${ }^{d}$, ZM607, KILIMA, P84 & 33 & 15 \\
\hline G & Mexico subtropical & 41 & CML, MBR, SPMAT, Pop33, Pop45, Pop501, Pop502 & 25 & 16 \\
\hline H & Mexico tropical & 44 & $C M L, C L Q, C L$ & 23 & 21 \\
\hline । & Selection under drought & 52 & DTPW, DTPYc, LPS & 41 & 11 \\
\hline J & Selection under low nitrogen & 32 & DTPW, DTPY, LPS & 24 & 8 \\
\hline Total & & 296 & & 196 & 100 \\
\hline
\end{tabular}

${ }^{\mathrm{a}} \mathrm{CML}$ CIMMYT maize line

${ }^{\mathrm{b}}$ DTPW Drought tolerant population white

${ }^{c} D T P Y$ Drought tolerant population white

${ }^{\mathrm{d}} M B R$ multiple borer resistant

e LPS La Posta Sequia 
Table 9 Locations, number of inbred lines and year of evaluation, rainfall, and relative humidity during growing season of the DTMA panel for common rust disease

\begin{tabular}{lllllllll}
\hline Experimental location & Year & Code & Number of lines & Planting date & Harvest date & Type of inoculation & Rainfall (mm) & Relative humidity \\
\hline El Batan, Mexico (Site 1) & 2009 & BM09A & 295 & 16 Apr 2009 & 27 Oct 2009 & Artificial & 725 & 65.9 \\
El Batan, Mexico (Site 2) & 2009 & BM09B & 295 & 16 Apr 2009 & 27 Oct 2009 & Natural & 725 & 65.9 \\
Embu, Kenya & 2009 & Kenya09 & 292 & 26 Oct 2009 & 30 Mar 2010 & Natural & 578 & 72.2 \\
El Batan, Mexico & 2010 & BM10 & 294 & 8 June 2010 & 8 Dec 2010 & Artificial & 790 & 76.2 \\
El Batan, Mexico & 2011 & BM11 & 296 & 12 May 2011 & 2 Nov 2011 & Artificial & 760 & 71.0 \\
Celaya, Mexico & 2012 & Celaya12 & 296 & 13 June 2012 & 16 Nov 2012 & Natural & 475 & 63.5 \\
\hline
\end{tabular}

$$
\mathrm{MDR}=\sum_{i=1}^{n}\left(X_{i}\right) / n
$$

where $i=$ time measures as days after planting when rust rating was conducted and $X i=$ rust rating.

AUDPC was calculated as:

$$
\text { AUDUPC }=\sum_{i=1}^{n}\left[\left(X_{i}+X_{i+1}\right) / 2\right]\left(T_{i+1}-T_{i}\right)
$$

where $i=$ time of rust rating, $T i=$ number of days after inoculation and $X_{i}=$ rust rating [45]. A third parameter, the final disease rating score (FDR, the third disease rating) was included in the analysis. The MDR, FDR, and AUDPC were used as parameters for statistical analysis and association mapping. Other parameters recorded included days to anthesis (AD) and days to silking (SD), which were used as covariates in GWAS computations, to ascertain whether rust resistance or susceptibility was associated with maturity.

\section{Statistical analysis of phenotypic data}

Phenotypic data from each experiment was analyzed for genotypic effects and genotype-environment interactions using the PROC MIXED command of SAS [46]. As lines were scored three times within a season, best linear unbiased predictions (BLUPs) were calculated from a multivariate mixed model for each rating, and a rust index was calculated by averaging the three BLUPs for each line. Repeatability was estimated for the MDR, FDR and AUDPC in a single location and across environments according to Holland et al. [47]. Pearson correlation coefficient between

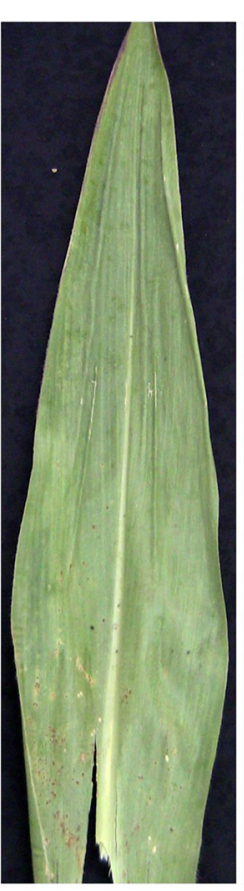

1

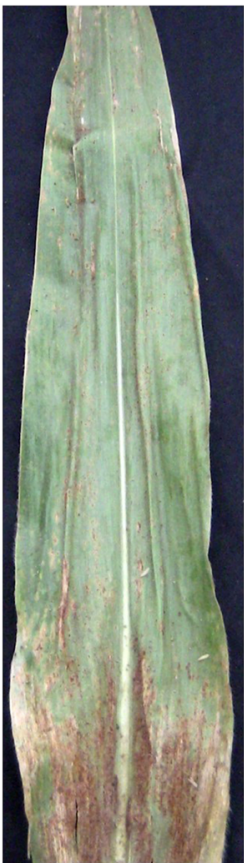

2

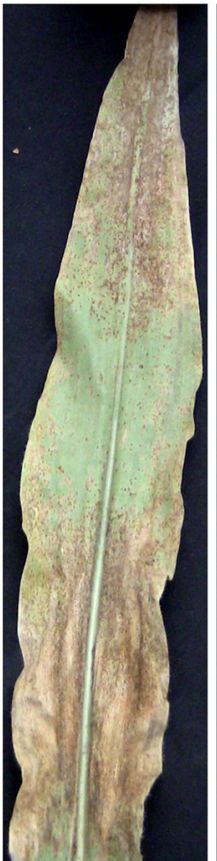

3

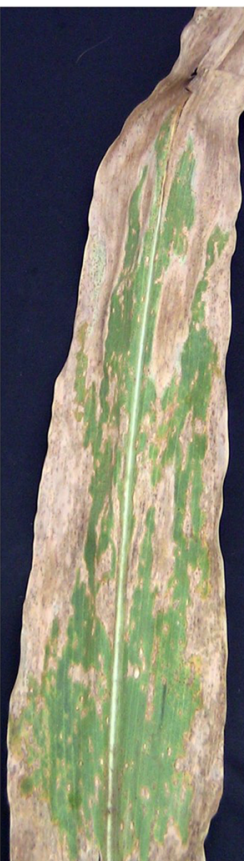

4

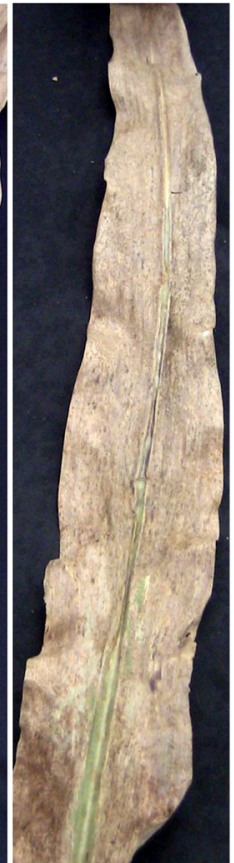

5

Fig. 4 Rating scale used to classify maize inbred lines into disease severity classes. Disease was scored on five-point scale based on the percent leaf area affected by pustules where $1=0$ to $10 \%$ of leaf surface diseased, $2=10$ to $25 \%$ of leaf surface diseased, $3=25$ to $50 \%$ of leaf surface diseased, $4=50$ to $75 \%$ of leaf surface diseased, and $5=$ over $75 \%$ of leaf surface diseased 
different phenotypic traits were calculated using the PROC CORR option in SAS [46]. Genotypic correlations $\left(\mathrm{r}_{\mathrm{g}}\right)$ between locations were estimated according to Cooper et al. [48] as:

$$
r_{g(12)}=r_{p(12)} /\left(H_{1}^{2} \times H_{2}^{2}\right)^{1 / 2}
$$

in which $r_{p(12)}$ is the phenotypic correlation between the traits measured in locations 1 and $2, \mathrm{H}^{2}{ }_{1}$ and $\mathrm{H}^{2}{ }_{2}$ are the values of broad-sense heritability for the traits measured in locations 1 and 2, respectively. Cluster analysis using Ward's minimum variance method [49] was performed to group environments based on genetic correlations among the environments. The SAS commands PROC CLUSTER and PROC TREE were used for cluster analysis and to generate the dendrogram, respectively.

\section{Single nucleotide polymorphism (SNP) genotyping and genome-wide association analysis}

Leaf samples were harvested from 10 plants of each line and bulked for extraction of total genomic DNA. All lines were genotyped using Illummina maize BeadChip with 56,110 SNP markers. Markers with a minor allele frequency (MAF) less than $5 \%$ in the lines were excluded from subsequent analyses. For the 56,110 SNPs contained in the chip, 32,051 SNPs were used for association mapping after removing SNPs with low MAF. Population structure and kinship were estimated according to $\mathrm{Lu}$ et al. [50]. Population diversity and principal component analysis (PCA) were conducted to visualize the genetic structure, and pairwise relatedness coefficients (kinship matrix) were calculated using TASSEL 3.0 [51]. Neighbor-joining tree and principal component analyses (PCA) were used to infer population structure of the GWAS panel. PCA and genetic relationship matrix were conducted in R software and exactly as described by Mahuku et al. [26]. Genome-wide association analysis was conducted using a mixed linear model (MLM) separately for each environment, as described by Mahuku et al. [26]. The $p$ values for each marker were combined using Fisher method as described by Chen [52] and the result used to make a Manhattan plot. The Bonferroni correction threshold [53] was used to obtain the Fisher combined $p$ value threshold.

\section{Candidate gene annotation}

To identify candidate genes in loci associated with rust resistance, we used public gene annotation datasets based on a filtered gene set of maize sequence (http://ensembl. gramene.org/Zea_mays/Info/Index). All the annotated genes within $\sim 200 \mathrm{~kb}$ of significant SNPs were retrieved based on known likely involvement as metabolic or signaling genes in disease resistance. These genes encode proteins containing a central domain with nucleotide binding site (NBS), which binds either ATP or GTP, and carboxy-terminal domain consisting of a series of degenerate leucine-rich repeat residues (LRR) in many crops [54-58].

\section{Linkage mapping}

The RIL population of 234 families from CML444 $\times$ MALAWI was genotyped with SNP markers using the KASP (Kompetitive Allele Specific PCR) system by LGC Genomics (https://www.lgcgroup.com) and used for genetic linkage map construction. The "Map" function in software QTL IciMapping [59] was used for linkage analysis. A logarithm-of-odds (LOD) threshold of 3.0 was used to declare linkage between two markers. The SNP marker physical position and "nnTwoOpt" algorithm in IciMapping were used to sequence the marker order. The Kosambi mapping function was used to calculate map distances [60]. The IciMapping method [59] was used for QTL mapping using QTL IciMapping. Scanning interval was set as $1 \mathrm{cM}$ between markers. Missing phenotypes were not used for the QTL analysis. The LOD threshold for QTL detection was set at 2.5. For QTL additive effects, positive and negative signs of the estimates indicated that resistance effects were contributed by MALAWI or CML444, respectively.

\section{Additional files} Additional file 1: The distribution of the common rust resistance in six
environments. (TIFF $935 \mathrm{~kb}$ )

Additional file 2: Response of inbred lines constituting the drought tolerant maize for Africa association mapping panel to common rust in different environments. (XLSX $34 \mathrm{~kb}$ )

Additional file 3: Pedigree of the tropical maize inbred lines constituting the drought tolerant maize for Africa (DTMA) panel. (XLSX $21 \mathrm{~kb}$ )

Additional file 4: $\mathrm{Q}-\mathrm{Q}$ plots of observed versus expected $-\log 10(P$ values) plots for common rust in different environments and using three disease evaluation parameters. FDR: Final disease rating; MDR: mean disease rating; and AUDPC: area under disease progress curve. (TIF $75 \mathrm{~kb}$ )

Additional file 5: Mean and range of rust resistance in the RIL population together with the variance components and heritability estimates in individual and combined environments. (DOCX $13 \mathrm{~kb}$ )

\section{Abbreviations}

AD: days to anthesis; AUDPC: Area under disease progress curve; DTMA: Drought Tolerant Maize for Africa; FDR: final disease rating; GWAS: Genome-wide association studies; MAF: Minor allele frequency; MDR: mean disease rating; MLM: Mixed linear model; QTL: quantitative trait locus (loci); RIL: Recombinant inbred line; SD: days to silking; SNP: single nucleotide polymorphism

\section{Acknowledgements}

The authors gratefully thank technical staff at the various locations for assistance with excellent trial management and data collection. The authors also thank Dr. Rodomiro Ortiz who provided insightful comments and suggestions on this paper.

\section{Funding}

This work was supported by the Bill and Melinda Gates Foundation through the project Drought Tolerant Maize for Africa (grant ID no. OPPGD1390) at CIMMYT. 


\section{Availability of data and materials}

Phenotypic data generated and analyzed during this study are included in this manuscript and its additional information files. SNP datasets used and/or analyzed during the current study are available from the corresponding author upon request.

\section{Authors' contributions}

GM and DM designed and performed the experiments; $\mathrm{HZ}, \mathrm{JC}, \mathrm{CM}, \mathrm{GM}$, and YX analyzed the data; GM, HZ, JC, CM, DM, and YX wrote the manuscript. All authors have read and approved the final manuscript.

\section{Ethics approval and consent to participate}

The germplasm used to set up experiments for this study was obtained from International Maize and Wheat Improvement Center breeding programs in Africa and Latin America. There were no additional approvals needed to collect leaf samples for genotyping.

\section{Consent for publication}

Not applicable.

\section{Competing interests}

The authors declare that they have no competing interests.

\section{Publisher's Note}

Springer Nature remains neutral with regard to jurisdictional claims in published maps and institutional affiliations.

\section{Author details}

${ }^{1}$ CIMMYT-China Specialty Maize Research Center, Shanghai Academy of Agricultural Sciences, Shanghai, China. ${ }^{2}$ Crop Breeding and Cultivation Research Institute, Shanghai Academy of Agricultural Sciences, Shanghai, China. International Maize and Wheat Improvement Center (CIMMYT), Apdo, Postal 6-641, 06600 Mexico, DF, Mexico. ${ }^{4}$ College of Life Sciences, Synergetic Innovation Center of Henan Grain Crops and National Key Laboratory of Wheat and Maize Crop Science, Henan Agricultural University, Zhengzhou 450002, China. ${ }^{5}$ Maize Research Institute, Shandong Agricultural Academy of Sciences, Jinan, China. ${ }^{6}$ International Maize and Wheat Improvement Center (CIMMYT), P.O Box 1041-00621, Nairobi, Kenya. IInstitute of Crop Sciences, Chinese Academy of Agricultural Sciences, Beijing, China. ${ }^{8}$ International Institute of Tropical Agriculture (IITA), P.O. Box, 34443, Dar es Salaam, Tanzania.

Received: 12 May 2018 Accepted: 13 November 2018

\section{Published online: 29 November 2018}

\section{References}

1. Vivek BS, Odongo O, Njuguna J, Imanywoha J, Bigirwa G, Diallo A, Pixley K. Diallel analysis of grain yield and resistance to seven diseases of 12 African maize (Zea mays L.) inbred lines. Euphytica. 2010;172:329-40.

2. Shah DA, Dillard HR. Yield loss in sweet corn caused by Puccinia sorghi: a meta-analysis. Plant Dis. 2006;90:1413-8.

3. Lübberstedt $T$, Klein D, Melchinger AE. Comparative quantitative trait loci mapping of partial rust resistance to Puccinia sorghi across four populations of European flint maize. Phytopathology. 1998:88:1324-9.

4. Davis DW, Randle WM, Groth JV. Some sources of partial resistance to common leaf rust (Puccinia sorghi) in maize and strategy for screening. Maydica. 1988;33:1-13.

5. Delaney DE, Webb CA, Hulbert SH. A novel rust resistance gene in maize showing overdominance. Mol Plant-Microbe Interact. 1998;11:242-5.

6. Kerns MR, Dudley JW. Rufener GK. QTL for resistance to common rust and smut in maize. Maydica. 1999;44:37-45.

7. Wisser RJ, Balint-Kurti PJ, Nelson RJ. The genetic architecture of disease resistance in maize: a synthesis of published studies. Phytopathology. 2006; 96:120-9.

8. Olukolu BA, Tracy WF, Wisser R, De Vries B, Balint-Kurti PJ. A genome-wide association study for partial resistance to maize common rust. Phytopathology. 2016;106:745-51.

9. Hulbert SH. Structure and evolution of the rp1 complex conferring rust resistance in maize. Annu Rev Phytopathol. 1997;35:293-310.

10. Hu G, Richter TE, Hulbert SH, Pryor T. Disease lesion mimicry caused by mutations in the rust resistance gene rp1. Plant Cell. 1996;8:1367-76.
11. Rhoades RH. The location of a gene for disease resistance in maize. Proc Natl Acad Sci U S A. 1935;21:243-6.

12. Saxena KMS, Hooker AL. On the structure of a gene for disease resistance in maize. Proc Natl Acad Sci U S A. 1968;61:1300-1305.

13. Hulbert SH, Bennetzen JL. Recombination at the Rpl locus of maize. Mol Gen Genet. 1991;226:377-82.

14. Pataky JK, JPate MC. Resistance genes in the $r p 1$ region of maize effective against Puccinia sorghi virulent on the Rp1-D gene in North America. Plant Dis. 2001;85:165-8.

15. Hagan WL, Hooker AL. Genetics of reaction to Puccinia sorghi in eleven corn inbred lines from central and South America. Phytopathology. 1965;55:193-7.

16. Hulbert SH, Lyons PC, Bennetzen JL. Reactions of maize lines carrying Rp resistance genes to isolates of the common rust pathogen, Puccinia sorghi. Plant Dis. 1991;75:1130-3.

17. Collins NC, Webb CA, Seah S, Ellis JG, Hulbert SH, Pryor A. The isolation and mapping of disease resistance gene analogs in maize. Molecular Plant Microbe Interaction. 1998;11:968-78.

18. Ayliffe MA, Steinau M, Park RF, Rooke L, Pacheco MG, Hulbert SH, Trick HN, Pryor AJ. Aberrant mRNA processing of the maize Rp1-D rust resistance gene in wheat and barley. Molecular Plant Microbe Interaction. 2004;7:853-64.

19. Smith SM, Pryor AJ, Hulbert SH. Allelic and haplotypic diversity at the Rp1 rust resistance locus of maize. Genetics. 2004;167:1939-47.

20. Nelson RR. Genetics of horizontal resistance to plant diseases. Annu Rev Phytopathol. 1978;16:359-78.

21. Parlevliet JE. Components of resistance that reduce the rate of epidemic development. Annu Rev Phytopathol. 1979;17:203-22.

22. Robertson DS. Understanding the relationship between qualitative and quantitative genetics. In: Helentjaris T, Burr B, editors. Development and application of molecular markers to problems in plant genetics. Cold Spring Harbor, NY: Cold Spring Harbor Laboratory Press; 1989. p. 81-8.

23. Helentjaris T, Slocum M, Wright S, Schaefer A, Nienhuis J. Construction of genetic linkage maps in maize and tomato using restriction fragment length polymorphisms. Theor Appl Genet. 1986;72:761-9. https://doi.org/10. 1007/BF00266542.

24. Brown AF, Juvik JA, Pataky JK. Quantitative trait loci in sweet corn associated with partial resistance to Stewart's wilt, northern corn leaf blight. and common rust Phytopathology. 2001;91:293-300.

25. Asea G, Vivek BS, Bigirwa G, Lipps PE, Pratt RC. Validation of consensus quantitative trait loci associated with resistance to multiple foliar pathogens of maize. Phytopathology. 2009;99:540-7.

26. Mahuku G, Chen J, Shrestha R, Narro LA, Guerrero KVO, Arcos AL, Xu Y. Combined linkage and association mapping identifies a major QTL (qRtsc8-1), conferring tar spot complex resistance in maize. Theor Appl Genet. 2016;129:1217-29.

27. Flint-Garcia SA, Thuillet AC, Yu J, Pressoir G, Romero SM, Mitchell SE, Doebley J, Kresovich S, Goodman MM, Buckler ES. Maize association population: a high-resolution platform for quantitative trait locus dissection. Plant J. 2005:44:1054-64.

28. Yan J, Warburton M, Crouch J. Association mapping for enhancing maize (Zea mays L.) genetic improvement. Crop Sci. 2011;51:433-49.

29. Liu W, Gowda M, Steinhoff J, Maurer H, Würschum T, Longin C, Cossic F, Reif J. Association mapping in an elite maize breeding population. Theor Appl Genet. 2011;123:847-58.

30. Li X, Zhou Z, Ding J, Wu Y, Zhou B, Wang R, Ma J, Wang S, Zhang X, Xia Z, Chen J, Wu J. Combined linkage and association mapping reveals QTL and candidate genes for plant and ear height in maize. Front Plant Sci. 2016;7:833.

31. Bailey BA, Wolfgang S, Frederiksen RA, Bockholt AJ, Smith JD. Identification of slow-rusting resistance to Puccinia polysora in maize inbreds and single crosses. Plant Dis. 1987;71:518-21.

32. Russell WA, Hooker AL. Location of genes determining resistance to Puccinia sorghi Schw. in corn inbred lines Crop Sci. 1962;2:477-80.

33. Kim SK, Brewbaker JL. Inheritance of resistance of sweet corn inbred II677a to Puccinia sorghi. Hortscience. 1987;22:1319-20.

34. Gingera GR, Davis DW, Groth JV. Identification and inheritance of delayed first pustule appearance to common leaf rust in sweet corn. J Am Soc Hortic Sci. 1995;120:667-72.

35. Holland JB, Uhr DV, Jeffers D, Goodman MM. Inheritance of resistance to southern corn rust in tropical-by-corn-belt populations. Theor Appl Genet. 1998;96:232-41.

36. Parlevliet JE. Durable resistance. In: Hartleb H, Heitefuss R, Hoppe HH, editors. Resistance of crop plants against Fungi, Gustav fisher, Jena Germany; 1997. p. 238-53. 
37. Futrell MC, Hooker AL, Scott GE. Resistance in maize to corn rust, controlled by a single dominant gene. Crop Sci. 1975;15:597-9.

38. Davis DW, Engelkes CA, Groth JV. Erosion of resistance to common leaf rust in exotic-derived maize during selection for other traits. Phytopathology. 1990;80:339-42.

39. Holland JB. Implementation of molecular markers for quantitative traits in breeding programs - Challenges and opportunities. In T. Fischer (ed.) New directions for a diverse planet. Proc. of the 4th Int. Crop Science Congress, Brisbane, QLD, Australia. 26 Sept.-1 Oct. 2004. Available at www. cropscience.org.au/icsc2004/.

40. Carson ML, Stuber CW, Senior ML. Identification and mapping of quantitative trait loci conditioning resistance to southern leaf blight of maize caused by Cochliobolus heterostrophus race O. Phytopathology. 2004; 94:862-7.

41. Liu L, Tan J, Zhang YD, Li HY, Bi YQ, Yu LJ, Jeffers DP, Kang MS fan XM. QTL mapping for gray leaf spot resistance in a tropical maize population. Plant Dis. 2016:100:304-12.

42. Huang X, Zhao Y, Wei X, Li C, Wang A, Zhao Q, Li W, Guo Y, Deng L, Zhu C, Fan D, Lu Y, Weng Q, Liu K, Zhou T, Jing Y, Si L, Dong G, Haung T, Lu T, Feng Q, Qian Q, Li J, Han B. Genome-wide association study of flowering time and grain yield traits in a worldwide collection of rice germplasm. Nature Gen. 2012:44:32-41.

43. Patterson HD, Williams ER. A new class of resolvable incomplete block designs. Biometrika. 1976;63:83-92.

44. Messmer R, Fracheboud Y, Banziger M, Vargas M, Stamp P, Ribaut JM. Drought stress and tropical maize: QTL-by-environment interactions and stability of QTLs across environments for yield components and secondary traits. Theor Appl Genet. 2009;119:913-30.

45. Shaner G, Finney RE. The effect of nitrogen fertilizer on the expression of slow-mildewing resistance in Knox wheat. Phytopathology. 1977;67:1051-6.

46. SAS Institute. SAS/STAT user's quide. SAS Institute, Cary, NC. 2008.

47. Holland JB, Nyquist WE, Cervantes-Martinez $C$. Estimating and interpreting heritability for plant breeding: an update. Plant Breed Rev. 2003;22:9-112.

48. Cooper M, DeLacy IH, Basford KE. Relationships among analytical methods used to analyze genotypic adaptation in multi-environment trials. In: Cooper M, Hammer GL, editors. Plant adaptation and crop improvement. Wallingford, UK: CAB Int; 1996. p. 193-224.

49. Ward JH. Hierarchical grouping to optimize an objective function. J Am Stat Assoc. 1963;58:236-44.

50. Lu Y, Zhang S, Shah T, Xie C, Hao Z, Li X, Farkhari M, Rubaut JM, Cao M, Rong $T, X u$ Y. Joint linkage-linkage disequilibrium mapping is a powerful approach to detecting quantitative trait loci underlying drought tolerance in maize. Proc Natl Acad Sci U S A. 2010;107:19585-90.

51. Bradbury PJ, Zhang Z, Kroon DE, Casstevens TM, Ramdoss Y, Buckler ESTASSEL. Software for association mapping of complex traits in diverse samples. Bioinformatics. 2007:23:2633-5.

52. Chen $\mathrm{Z}$. Is the weighted $\mathrm{z}$ test the best method for combining probabilities from independent tests? J Evol Biol. 2011:24:926-30.

53. Bland JM, Altman DG. Multiple significance tests: the Bonferroni method. BMJ. 1995:310:170

54. Landsculz WH, Johoson PF, McKnight SL. The leucine zipper: a hypothetical structure common to a new class of DNA binding proteins. Science. 1988; 240:1759-62.

55. Kobe B, Deisenhofer J. The leucine - rich repeat: a versatile binding motif. Trends Biochem Sci. 1994;19:415-21.

56. Jones DA, Jones JDG. The roles of leucine-rich repeat proteins in plant defenses. Adv Bot Res. 1996;24:89-167.

57. Hammond-Kosack KE, Jones JDG. Plant disease resistance genes. Annu Rev Plant Physiol Plant Mol Biol. 1997;48:575-607.

58. Webb A, Richter TE, Collins NC, Nicolas M, Trick HN, Pryor T, Hulbert SH. Genetic and molecular characterization of the maize rp3 rust resistance locus. Genetics. 2002;162:381-94.

59. Wang J, Li H, Zhang L, Meng L. Users' manual of QTL IciMapping Version 3. 2. The Quantitative Genetics Group, Institute of Crop Sci, Chinese Academy of Agric Sci (CAAS), Beijing 100081, China, and Genetic Resources Program, International Maize and Wheat Improvement Center (CIMMYT), Apdo. Postal 6-641, 06600 Mexico, D.F., Mexico. 2012.

60. Kosambi DD. The estimation of map distances from recombination values. Annals Human Gen. 1944;12:172-5.

\section{Ready to submit your research? Choose BMC and benefit from:}

- fast, convenient online submission

- thorough peer review by experienced researchers in your field

- rapid publication on acceptance

- support for research data, including large and complex data types

- gold Open Access which fosters wider collaboration and increased citations

- maximum visibility for your research: over $100 \mathrm{M}$ website views per year

At BMC, research is always in progress.

Learn more biomedcentral.com/submissions 